\title{
Para una historiografía de la religión hispanorromana en el marco de la civitas: el paradigma de los cultos locales en el noroeste
}

Mª Cruz González-Rodríguez

Universidad del País Vasco. UPV/EHU

cruz.gonzalez@ehu.eus

Fecha recepción 01.05.2017 / Fecha aceptación 30.09.2017

\section{Resumen}

Esta contribución pretende ofrecer un balance historiográfico de los trabajos más significativos llevados a cabo en el presente siglo sobre la religión hispanorromana (s. I-s. III d. C.) y reflexionar sobre los avances conseguidos en la investigación con respecto al s. XX. El camino que trazamos se centra en los logros alcanzados en tres cuestiones básicas: los sacerdocios; los cultos (con especial atención a los cultos locales del Noroeste) y los lugares de culto. Para finalizar se apuntan las lagunas y los caminos que aún quedan por recorrer.

\section{Palabras clave}

Religión hispanorromana, Hispania, Noroeste, sacerdocios, lugares de culto, cultos locales, religio, civitas

\section{Abstract}

This paper aims to offer a historiographic summary of the most significant contributions of this century concerning the religion of Roman Hispania (1st-3rd c. A.D.) in order to reflect on the progress of research conducted since the 20th century. We will focus on the achievements in three fundamental areas: priesthood, cults (especially the local cults of the NW) and places of worship. Finally, mention is made concerning research gaps and issues that should be addressed in the future.

\section{Keywords}

Religion the Roman Hispania, Hispania, Northwest, priesthood, places of worship, local cults, religio, civitas. 

ES INDUDABLE QUE EN LOS MÁS DE TRES LUSTROS QUE LLEVAMOS del presente siglo se han producido cambios y avances en el conocimiento de la religión hispanorromana, tanto a nivel cuantitativo como cualitativo ${ }^{1}$.

A nivel cuantitativo ha habido un incremento considerable de fuentes, sobre todo epigráficas tal y como se puede comprobar al consultar las dos publicaciones periódicas de referencia en este campo: Hispania Epigraphica y Ficheiro Epigráfico a las que se deben sumar (además de L’Année Epigraphique) los corpora locales o provinciales que han visto la luz a lo largo de estos últimos diecisiete años. Igualmente, el desarrollo de nuevas excavaciones puntuales y la continuidad de otras han proporcionado también nuevas informaciones o aclarado los problemas relacionados con las características de algunos lugares de culto, tal y como se puede observar, por ejemplo, en los casos de las actuales ciudades de Écija (Sevilla) en la Bética o Tarragona en la Citerior ${ }^{2}$. Este es un logro sumamente importante -pues la

1. Este trabajo se ha realizado en el marco de los proyectos HAR2011-25370 y HAR2015-65526-P (MINECO/FEDER, UE) así como dentro del grupo de investigación IT698-13 del Sistema Universitario Vasco. Agradecemos a los evaluadores externos de esta contribución sus útiles comentarios que, sin duda, han contribuido a mejorar la redacción final.

2. En el caso de la actual Écija las excavaciones llevadas a cabo entre 1997 y 2007 en la plaza de España han proporcionado interesantes hallazgos arqueológicos y epigráficos que ilustran las características de un área sacra en el foro de una colonia hispana, tal y como puede verse, por ejemplo, en S. Ordóñez Agulla, S. García-Dils de la Vega y J.C. Saquete Chamizo, "Dos nuevos pedestales epigráficos de Colonia Augusta Firma Astigi (Écija, Sevilla)", Zephyrus, LXX, julio-diciembre 2012, 191-202. Por su parte, en la ciudad de Tarragona las excavaciones que se vienen realizando, desde el año 2000, en el recinto y entorno de la catedral (J.M. Macías i Solé, J. Menchón i Bes, A. Múñoz e I. Teixell Navarro, "Excavaciones arqueológicas en la catedral de Tarragona (2000-2002)”, Arqueología de la Arquitectura, 2, 2003, 167-175) han permitido un mejor conocimiento de los edificios de culto imperial a nivel provincial. En este sentido cabe destacar muy especialmente, la propuesta de R. Mar, J. Ruiz de Arbulo y D. Vivó sobre la restitución de la gran aedes flavia que presidía el área sagrada del foro provincial de Tarraco donde podría ubicarse el ciclo icónico dedicado a los Genii de los conventus jurídicos de la PHC: R. Mar, J. Ruiz de Arbulo y D. Vivó, "Los genios 
materia prima del historiador son las fuentes- pero no lo es menos el hecho de que estas fuentes deben ser explicadas en un marco de análisis adecuado y coherente, y es en este nivel, en el cualitativo, donde los avances -en nuestra opinión- resultan ser, a nivel general, menos significativos o si se quiere, menos visibles.

Es precisamente en este tipo de logros a los que nos queremos referir y sobre los que pretendemos reflexionar. Para ello, aunque pueda parecer obvio, lo primero que conviene hacer es explicar el propio título de nuestra contribución y determinar a qué nos estamos refiriendo cuando hablamos de religión hispano romana y cuál es -desde nuestro punto de vista- el modelo explicativo más apropiado para su estudio y comprensión.

\section{La religión cívica}

Hablar de la religión hispanorromana significa hablar de religión romana provincial en el occidente del imperio con una problemática similar a la religión de las provincias de las Galias, Germanias o Britania ${ }^{3}$. Los distintos momentos en que estos territorios se integran en el im-

de los conventus iuridici y el lugar de reuniones del concilium provinciae Hispaniae Citerioris ¿una curia de uso provincial en Tarraco?", en B. Soler, P. Mateos, J. Miguel Noguera y J. Ruiz de Arbulo (eds.), Las sedes de los ordines decurionum en Hispania. Análisis arquitectónico y modelo tipológico, Mérida, 2013, 2542. No es nuestra intención llevar a cabo una enumeración exhaustiva de todos los trabajos realizados sobre la temática que aquí abordamos (tarea que excede con creces los límites de esta contribución) y nos centraremos, sobre todo, en aquellas contribuciones que resultan, en nuestra opinión, más significativas para conocer los avances producidos en el campo de estudio de la religión hispanorromana.

3. Pueden verse, entre otros, para las Galias: W. Van Andringa, La religion en Gaule romaine. Piété et politique ( ${ }^{e r-I I I}$ siècle apr. J.-C.), París, 2002; id., "Religions and the Integration of Cities in the Empire in the Second Century AD: The Creation of a Common Religious Language", en J. Rüpke (ed.), A Companion to Roman Religion, Oxford, 2007, 83-95; id., "New Combinations and New Statuses. The Indigenous Gods in the Pantheons of the Cities of Roman Gaul", en J.A. North y S.R.F. Price (eds.), The Religious History of the Roman Empire. Pagans, Jews and Christians, Oxford, 2011, 109-138. A estos estudios deben añadirse las aportaciones de R. Haüssler, como es el caso de su trabajo titulado "Au-delà de la religion poliade: cité et religion en Gaule Narbonnaise", Revue archéologique de Narbonnaise, 43, 2010 (2013), 67-84 y las contribuciones recogidas por M.-O. Charles-Laforge (Études réunies par), Les religions dans le monde romain. Cultes locaux et dieux romains en Gaule de la fin de la République au III siècle après J.-C.: persistance ou interpretatio?, Arras, 2014 y M.Th. Raepsaet-Charlier, "Cultes et territoire, Mères et Matrones, dieux 'celtiques'. Quelques aspects de la religion dans les provinces romaines de Gaule et de Germanie à la lumière de travaux recents", L'Antiquité classique, 84, 2015, 173-226. Para las Germanias: W. Spickermann, "Les provinces germaniques: un champ d'analyses pour l' histoire des religions", en Rome et l' Occident (IIe siècle av. J.-C.-IIe siècle apr. J.-C.). Gouverner l'Empire, Rennes, 2009, 451-490 y en este mismo volumen puede verse para Britania: R. Haüssler, "La religion en Bretagne", 491-523. Para el norte de África: E. Smadja, "La religion civique en Afrique du Nord sous le Haut-Empire romain: africanité et romanisation, quelques exemples", en Charles-Laforge (Études réunies par), Les religions... op. cit., 15-30. En general, sobre el estudio de la religión romana provincial puede consultarse: R. Haüssler, (Ed.), Romanisation et épigraphie. Études interdisciplinaires sur l'acculturation et l'identité dans l'Empire romain, Montagnac, 2008; id., Becoming Roman? Diverging Identities and Experiences in Ancient Northwest Italy, California, 2013; R. Haüssler y 
perio romano marcan la construcción del sistema religioso provincial en época romana que conviene analizar en el marco de un modelo explicativo convertido ya en clásico desde hace unos treinta años, el de la religión cívica. Este modelo, a pesar de las críticas recibidas en el s. $\mathrm{XX}$ por parte, sobre todo, de la historiografía anglosajona $-\mathrm{y}$ rebatidas de forma contundente, en nuestra opinión, por J. Scheid, tal y como se puede ver de forma clara en su monografía del $2013^{4}$ - sigue siendo totalmente operativo y muy útil para ayudar a comprender la religión romana provincial.

Este marco explicativo que sitúa a la civitas en el centro de la religión romana provincial enmarcando la cuestión religiosa en el orden institucional instaurado por Roma encuentra en las provincias hispanas un lugar privilegiado pues no en vano en la provincia de la Bética han sido hallados los dos textos legales -leyes de la colonia de Urso (Lex coloniae Genitivae Iuliae) y del municipio de $\operatorname{Irni}^{5}$ (Lex Irnitana) - que sirven de referencia para entender el funcionamiento de la religio en las civitates romanas provinciales. Estas leyes demuestran que en el momento de la constitución de estas comunidades sus autoridades competentes establecen sus panteones; sus sacerdotes o agentes de culto; la organización de los sacra; los fondos para sufragarlos y los lugares de culto.

El sistema religioso que se deduce de ambas normativas y del resto de epígrafes sagrados es resultado del proceso de integración de las comunidades locales en el Imperio romano

A.C. King (eds.), Continuity and Innovation in Religion in the Roman West (in part Proceedings of the 6th International F.E.R.C.AN. Workshop, Londres, April 2005), Journal of Roman Archaeology, Supplementary vol., 67, 2008, part 2.

4. J. Scheid, Les dieux, l'État et l'individu. Réflexions sur la religion civique à Rome, París, 2013. Este investigador ha llevado a cabo numerosos e interesantes trabajos en los que plantea un profundo análisis de la religión cívica romana. Pueden verse, entre otros: $i d$., Quand faire c'est croire. Les rites sacrificiels des Romains, París, 2005; id." "Réflexions sur le Mars trévire", en V. Brouquier-Reddé y E. Bertrand et alii (eds.), Mars en occidente. Actes du Colloque international 'Autour d'Allonnes (Sarthe)', les sanctuaires de Mars en Occident, Rennes, 2006, 35-44 e id. y F. de Polignac, "Qu'est-ce qu' un 'paysage religieux'? Représentations cultuelles de l'espace dans les sociétés anciennes", Revue de l' histoire des religions, 4, 2010, 427-434. En la misma línea se deben citar también los análisis de Van Andringa mencionados en la nota anterior.

5. CIL II $2 / 5,1022$ y $A E 1986,333$. Los asuntos relacionados con la religio se recogen en diferentes capítulos: Ley de Urso, capítulos 62, 64, 65, 66, 67, 68, 70, 71; 81, 91, 128 y ley de Irni: capítulos 19, 25, 26, 59, 69, 73, 77, 79 y 92 . En conjunto, ambas leyes nos permiten conocer el marco de referencia obligado para la comprensión de la religión cívica provincial. Sobre el contenido de estas leyes en materia religiosa véase, entre otros, J. Scheid, "Aspects religieux de la municipalisation. Quelques réflexions générales", en M. Dondin-Peyre y M.Th. Raepsaet-Charlier (eds.), Cités, Municipes, Colonies. Les processus de municipalisation en Gaule et en Germanie sous l' Haut Empire Romain, París, 2009, 381-423; Mª.C. González-Rodríguez, "La religión en la ciudad romana: el ejemplo hispano (s. I a. C. - s. III d.C.)”, en J. Bartolomé, Ma.C. González-Rodríguez y M. Quijada (eds.), La escritura y el libro en la Antigüedad, Madrid, 2004, 151-170; A. Raggi, "Le norme sui sacra nelle leges municipales", en L. Capogrossi y E. Gabba (dir.), Gli statuti municipali, Pavía, 2006, 701-721; J.F. Rodríguez Neila, "Sociedad municipal y sacra publica. A propósito de un relieve de Luggdunum (Lyon)”, en J. Mangas y M.A. Novillo (eds.), Santuarios suburbanos y del territorio de las ciudades romanas. (Madrid 2829 de mayo de 2009), Madrid, 2014, 87-112.

Revista de historiografía 28, 2018, pp. 73-94 
y de las medidas llevadas a cabo para organizar los territorios conquistados (deducción de colonias; conversión de civitates peregrinas en municipios; otorgamiento del Ius latii... $)^{6}$. En consecuencia, la religio de las distintas civitates, que en algunas zonas de la Península, especialmente en el norte, son construcciones de los primeros siglos del imperio, viene marcada, entre otras circunstancias, por las diferencias en el desarrollo histórico alcanzado por las distintas comunidades; por los ritmos y los tiempos de la conquista (muy distintos si nos referimos al sur y levante peninsular o al noroeste y norte) y su integración en el mundo romano y por la disparidad en sus estatutos jurídicos ${ }^{7}$.

En la nueva religión ciudadana y comunitaria surgida de la conquista, y de los correspondientes procesos de urbanización y romanización, y caracterizada por el politeísmo -y que como tal procede por agregación y no por exclusión-, tenían cabida tanto los dioses romanos y mediterráneos como los denominados dioses «indígenas»o «prerromanos» que en algunos casos y épocas se integran -como los devotos que les rinden culto- en los panteones de las nuevas comunidades cívicas.

Concebir la religión romana provincial y, en consecuencia, la hispanorromana de esta manera supone un cambio significativo con respecto a la visión que mayoritariamente ofrecía la historiografía tradicional del s. XX en la que hablar de religión hispanorromana significaba hablar de dioses, ritos y lugares de culto romanos ${ }^{8}$ separados y diferenciados de los denominados dioses, ritos y santuarios «indígenas» o «prerromanos» ${ }^{9}$. Sin embargo, investigaciones más recientes, siguiendo los planteamientos expuestos de forma clara a finales de la

6. Para el estudio de los procesos de reorganización de las civitates hispanas desde el s. II a. C. al s. II d. C. véase E. Ortiz-de-Urbina Álava, "Sobre los procesos de (re)organización institucional cívica en Hispania", en ead., (ed.), Magistrados locales de Hispania. Aspectos históricos, jurídicos, lingüísticos. (Anejos de Veleia. Acta 13), Vitoria-Gasteiz, 2013, 279-308.

7. Véase J. Alvar, "Las religiones en Hispania en el cambio de era”, en L. Hernández Guerra, L. Sagredo San Eustaquio y J.Ma Solana Sainz (coords.), La Península Ibérica hace 2000 años. Valladolid 23-25 de noviembre 2000, Valladolid, 2002, 119-128.

8. Baste citar al respecto la tesis doctoral de A.Ma Vázquez Hoys, La religión romana en Hispania: fuentes epigráficas, arqueológicas y numismáticas, Madrid, 1982 y algunas de las importantes contribuciones de J. Mangas en este campo, como por ejemplo: "Religiones romanas y orientales", en J.Ma Blázquez et alii, Historia de España Antigua. Tomo II. Hispania Romana, Madrid, 1978, 613-649; id., "Religión romana de Hispania”, en Historia de España fundada por R. Menéndez Pidal y dirigida por J.M. Jover, España Romana (218 a. de J.C. - 414 d. C.). La sociedad, el derecho, la cultura. Tomo II, Madrid, 1982, 323-369 e id., "Römische Religion in Hispanien", ANRW, II, 18.1, 1986, 276-344.

9. En este campo destacan muy especialmente los numerosos trabajos de J.M Báázquez, entre otros: Religiones primitivas de Hispania, Madrid, 1962; id., Diccionario de las religiones prerromanas, Madrid, 1975; id., Primitivas Religiones ibéricas II. Religiones prerromanas, Madrid, 1983; id. y F. Marco Simón, Historia de las religiones de la España antigua, Madrid, 1994 e id., Religiones, ritos y creencias funerarias en la Hispania prerromana, Madrid, 2001. Sobre la historiografía referida a las divinidades de Hispania puede verse ahora la interesante tesis doctoral de V. Salamanqués Pérez, La percepción de los dioses de Hispania por los autores españoles de los siglos XVI a XVIII. Universidad de Alcalá de Henares, Alcalá de Henares, 2017. Agradecemos a esta investigadora que nos haya permitido consultar esta investigación inédita. 
década de los 90 por F. Diez de Velasco ${ }^{10}$, aconsejan romper esta rígida división, tal y como ya ha sido señalado, más recientemente y para el sur peninsular, por C. Martínez Maza y J. Alvar al estudiar el panteón de Málaga ${ }^{11}$; por P. Le Roux al referirse al área indoeuropea ${ }^{12}$; por nosotros mismos en los trabajos sobre la religio del noroeste hispano ${ }^{13} \mathrm{y}$ muy recientemente por S. Alfayé Villa en su estudio sobre la ciudad romana de Clunia ${ }^{14}$ y valorar la integración de los dioses ajenos, los de los otros tomando en consideración las adaptaciones y cambios inevitables en el proceso de interacción e interdependencia entre la cultura dominante, la de Roma y las locales con las que entra en contacto. De ahí que resulte necesario estudiar la religión hispanorromana en el marco de los procesos de aculturación y del complejo fenómeno de la llamada interpretatio romana ${ }^{15}$.

10. F. Diez de Velasco, "Religión provincial romana en la Península Ibérica: reflexiones teóricas y metodológicas", en Religión y Magia en la Antigüedad. Seminario celebrado en Valencia del 16 al 18 de abril de 1997, Valencia, 1999, 89-102. Tal y como indicaba este investigador (p. 91): “...resulta necesario renunciar a la diferencia entre la religión indígena o prerromana y la religión romana. La primera no sería por tanto (...) más que un aspecto de la religión provincial, habida cuenta que, además, la pura religión prerromana no nos resulta accesible puesto que lo único que verdaderamente conocemos es la fase de contacto en la que se emplean soportes de tipo romano (como son los epígrafes) para transmitir la información que nos interesa".

11. C. Martínez Maza y J. Alvar, "El mundo de las creencias en la Málaga Romana", Mainake, 29, 2007, 357-375.

12. P. Le Roux, "Divinidades indígenas en la Hispania indoeuropea", Veleia, 16, 2009, 33-49.

13. Ma.C. González-Rodríguez, "Die lateinische Epigraphie Hispaniens als Quelle für die keltische Gesellschaft und Religion", Veleia, 18-19, 2001-2002, 39-60; ead., "Sobre la religio de los pueblos del NO durante el Alto Imperio: algunas observaciones", Palaeohispanica, 5, 2005, 775-792; ead., "Noms des divinités préromaines du Nord-Ouest Hispanique: bilan provisoir", en J. d' Encarnação (coord.), Divindades indígenas em análise. Divinités pré-romaines: bilan et perspectivas d'une recherche, Coimbra-Oporto, 2008, 81-104; ead., "Un ejemplo de romanización a través de la epigrafía latina altoimperial: los cultos indígenas en el Norte hispano", en J. Santos Yanguas y G. Cruz Andreotti (eds.), Romanización, fronteras y etnias en la Roma antigua: el caso hispano. (Anejos de Veleia. Acta 12) Vitoria-Gasteiz, 2012, 601-630 .

14. S. Alfayé Villa, “Expresiones religiosas en las ciudades del poder de la Hispania Céltica: el caso de Clunia", Revista de Historiografía, 25, 2016, 355-383.

15. Tal y como ya ha sido señalado, en general, para Hispania y, particularmente, para las ciudades del sur peninsular con ricas manifestaciones religiosas pluricultulares por J. Alvar, "Las religiones..., op. cit., 120, e id., "El panteón de Carmona: destellos de la vida religiosa en una ciudad hispanorromana", en A. Caballos (ed.), Carmona romana. Carmona, 29 septiembre a 2 octubre de 1999, Carmona, 2001, 477-489. Para el área indoeuropea los procesos de interpretatio vienen siendo estudiados desde hace tiempo por F. Marco Simón en diferentes trabajos entre los que destacamos: "Rethinking interpretatio as a key factor in the religious romanisation of the West", en G. Hily, P. Lajoye, J. Hascoët, G. Oudaer y Ch. Rose (Textes réunis par), Deuogdonion. Mélanges offerts en l'honneur du Professeur Claude Sterckx, Rennes, 2010, 413431; id., "Interpretatio romana y asimilación indígena. Recursos en la identificación de los dioses ajenos", en J. Cardim (coord.), DIIS . DEABVSQUE Actas do II Coloquio Internacional de Epigrafia "Culto e Sociedade", Sintria, III-IV (1995-2007), 2011, 307-340; id., "Patterns of interpretatio in the Hispanic provinces", en G.F. Chiai, R. Häussler y C. Kunst (eds.), Interpretatio. Religiöse Kommunikation zwischen Globalisierung und Partikularisierung. Proceedings of the conference at Osnabrück University, 9th-11th september 2010, Roma, 2012, 217-232 e id., "Local cult in global context: Interpretatio and the emergence of new divine identities 
Al mismo tiempo se debe tener en cuenta que la vida religiosa romana es de carácter comunitario y se manifiesta en agrupamientos de naturaleza muy variada que interaccionan y articulan sin problema con la religión cívica y de esta forma se encuentran diferentes sistemas cultuales en un mismo espacio (como es el caso del culto imperial provincial o conventual o los cultos del ejército). Cada uno de ellos, podríamos decir, otorga al devoto una identidad religiosa diferente no excluyente y todas ellas complementarias, tal y como se observa en un conocido epígrafe de Lugo (IRPL 23, AE 1980, 595 bis) ${ }^{16}$ de fines s. II-comienzos s. III dedicado por un liberto imperial ligado a África y que desarrolla sus labores administrativas en Lusitania y Gallaecia a los Numina imperiales, a Juno Reina, a Venus Victoriosa y a diferentes divinidades locales (vinculadas, respectivamente, a Cartago, Mérida y Gallaecia), es decir, una combinación divina de carácter mixto en la que tienen protagonismo tanto dioses locales como globales.

La asunción de estas premisas metodológicas - mayoritarias en la historiografía europea que se ocupa del estudio de la religión romana provincial y muy escasas en la historiografía hispana- junto con la utilización del método comparativo ha permitido, y permitirá, avances significativos en la comprensión de la religión hispanorromana.

Estos logros se detectan en el estudio de tres ámbitos muy significativos del paisaje religioso de la Hispania romana: en los collegia sacerdotales o agentes de culto; en los panteones locales y los cultos cívicos; en los cultos conventuales y provinciales; en los cultores y los loca sacra o lugares de culto.

\section{Collegia sacerdotales}

En el estudio de los collegia cívicos se ha avanzado considerablemente en el presente siglo y se puede afirmar que es la parcela sobre la que tenemos una visión más coherente y completa gracias, sobre todo y especialmente, a los trabajos continuados de J. Delgado Delgado ${ }^{17}$

in the provincia Tarraconensis", en A. Hofeneder y P. de Bernardo Stempel (eds.), Théonymie celtique, cultes, interpretatio / Keltische Theonymie, Kulte, interpretatio. X. Workshop F.E.R.C.AN., París, 24-26 Mai 2010, Viena, 221-232. Sobre el fenómeno de la interpretatio en diversos ámbitos del mundo antiguo puede encontrarse una reflexión interesante en F. Colin, O. Huck y S. Vausévereu (eds.), Interpretatio. Traduire l'altérité culturelle dans les civilisations de la l'Antiquité, París, 2015.

16. [Iovi Optimo Max(imo)] / [Numi]nib(us) [Aug]ustor(um) / [Iunioni R]e[gi]nae / Veneri Victrici / Africae Caelesti / Frugifero / Augustae Emeritae / et Larib(us) Callaeciar(um) / [S]aturninus Aug(usti) Lib(ertus). Este ejemplo materializa muy bien el paisaje religioso dominante en época imperial en el occidente del imperio en el que se dan nuevas combinaciones divinas en las que divinidades de distinto origen comparten tiempo y espacio sin problema. Sobre este sugerente texto véase, en último lugar: Van Andringa, "Religion and the Integration..., op. cit., 83-84.

17. J. Delgado Delgado, "Los sacerdotes de las ciudades del Occidente latino: una síntesis", Iberia, 3, 2000, 35-50; id., "Los sacerdotes de rango local de la provincia romana de Lusitania", Conimbriga, 39, 2000, 107152; id., "Los augures y el augurado en la Hispania romana: estudio sobre un sacerdocio de tradición romana en un ámbito provincial", Hispania Antiqua, 24, 2000, 67-85; id., "Los fasti sacerdotum de las ciudades de la Bética", Habis, 32, 2001, 297-332; id., "Los sacerdotes en el marco de las instituciones municipales en 
realizados siempre con un método de análisis impecable. Sus distintas investigaciones han demostrado y establecido que en Hispania se encuentran los mismos tipos de sacerdocios en colonias y municipios - un collegium de pontífices y otro de augures-. Por ello, hay que pensar que la diferencia de estatuto jurídico entre uno y otro tipo de ciudades no tuvo ninguna influencia en la organización sacerdotal. Igualmente, este investigador ha podido demostrar que las elites locales fueron las primeras interesadas en adoptar y difundir este modelo y que los cursus honorum de los sacerdotes locales, como ocurría en la propia Roma, contemplaban tanto funciones civiles (magistraturas) como religiosas y tanto unas como otras aparecen muy frecuentemente asociadas en las carreras de los notables locales. Pero como también sucedía en Roma, ni todos los magistrados obtenían sacerdocios, ni todos los sacerdotes accedían necesariamente a alguna magistratura.

Uno de sus trabajos más recientes ${ }^{18}$ es sin duda también uno de los más interesantes por abordar un problema histórico e historiográfico que hasta ahora no había sido analizado en detalle: el sacerdocio de los Salios de Sagunto, única ciudad provincial que contaba con esta sodalidad. El estudio prosopográfico de su reclutamiento y el análisis histórico-religioso del sacerdocio le ha permitido establecer que se trata de un unicum que materializa perfectamente la interacción entre la cultura romana y la conservadora aristocracia saguntina.

Por lo que respecta a los sacerdocios provinciales -además de los trabajos de J. Delgado Delgado-o (en su caso) conventuales del culto imperial, los estudios de los últimos años han dado un salto cualitativo importante en el estudio de su autorrepresentación, siendo claro ejemplo de ello los trabajos de B. Goffaux sobre los sacerdotes conventuales de la Hispania citerior y el origen de los flámines de la Bética ${ }^{19}$ así como los de E. Ortiz-de-Urbina y Ma ${ }^{\text {.C. }}$ Delia Gregorio para la Hispania citerior y de S. Panzram para la Bética ${ }^{20}$.

la Hispania romana”, en M. Cébeillac-Gervasoni y L. Lamoine (eds.), Les élites et leurs facettes. ClermontFerrand, 24-26 de noviembre de 2000, Roma-Clermont-Ferrand, 2002, 223-240; id., "Tiempo y espacio en las actividades públicas de los sacerdotes romanos", en D. Segarra (ed.), Transcurrir y Recorrer. La categoría espacio-temporal en las religiones del mundo clásico, Roma, 2003, 165-186; id., "Priests of Italy and the Latin provinces of the Roman empire", en V. Lambrinoudakis y J.Ch.- Balty (eds.), ThesCRA (Thesaurus Cultus et Rituum Antiquorum), V, Los Angeles-Basel, 2005, 116-139; id., "In demortui damnative loco..." (Lex Urs. LXVII)", en Espacios, usos y formas de la epigrafía hispana en épocas antigua y tardoantigua. Homenaje al Dr. Armin U. Stylow, Mérida, 2009, 103-108; id., "El flaminado local y provincial en Lusitania. Contribución a la historia política, social y religiosa de una provincia romana”, en J.L. Cardoso y M. Almagro-Gorbea (eds.), Lucius Cornelius Bocchus. Escritor Lusitano da Idade de Prata da Literatura Latina, Lisboa-Madrid, 2011, 231-244 e id., "El sacerdocio salio de Sagunto. La recepción del programa religioso de Augusto en un municipio de Hispania citerior", Veleia, 31, 2014, 143-162.

18. Ibidem... op. cit.

19. Para una valoración de la historiografía referida al culto imperial remitimos a la contribución de C. Alarcón en este mismo volumen. Baste citar aquí los estudios de B. Goffaux: "CIL II²/5, 311 (Igabrum) et la chronologie des premiers flamines de Bétique”, Archivo Español de Arqueología, 86, 2013, 261-278 e id., "Priest, conventus and provincial organisation in Hispania Citerior", en J.H. Richardson y F. Santangelo (eds.), Priests and State in the Roman World, Stuttgart, 2011, 445-469.

20. E. Ortiz-de-Urbina Álava, "Culto imperial y representación provincial en Hispania”, en Cristianos y paganos en Roma. III Ciclo de Conferencias sobre el Mundo Clásico, San Sebastián, 2007, 57-90; Mª.C.

Revista de historiografía 28, 2018, pp. 73-94 


\section{Cultos}

Por lo que atañe a los cultos cívicos, los panteones ciudadanos, lo primero que hay que subrayar es que su análisis parte de un problema irresoluble: el carácter fragmentario de la documentación (material y escrita), en demasiadas ocasiones descontextualizada, unido a la dificultad de establecer con seguridad, salvo casos concretos, los fines/límites de las diferentes civitates $^{21}$. En consecuencia, la visión que se puede ofrecer al respecto, en la mayoría de los casos, dista mucho de ser completa y segura. No obstante, a pesar de estas limitaciones insalvables se ha profundizado en el conocimiento de los sacra de diferentes ciudades romanas tal y como demuestran las distintas contribuciones recogidas en las monografías editadas, respectivamente, en 2002 y 2011 por L. Raposo y J. Cardim y en 2007 por T. Nogales y J. González sobre el culto imperial ${ }^{22}$. A estas se suman algunos otros trabajos referidos a una provincia, como es el caso del de J. Mangas sobre los cultos cívicos de la Bética ${ }^{23}$ y los abundantes estudios alusivos a los cultos en una ciudad concreta, como el de C. Martínez Maza y J. Alvar sobre el panteón de Málaga o el del último de estos dos investigadores ${ }^{24}$ sobre el de Carmona o los que se ocupan de las manifestaciones cultuales de un grupo de población o de un territorio ${ }^{25}$.

González-Rodríguez y E. Ortiz-de-Urbina Álava, "Élites locales de Hispania citerior a las puertas a de la élite imperial: observaciones a propósito del CIL II²/14, 1145 y 1188”, en A. Caballos y E. Melchor (eds.), De Roma a las provincias: las élites como instrumento de proyección de Roma. Juan Francisco Rodríguez Neila in honorem, Sevilla, 2015, 519-541; Ma.C. Delia Gregorio, "Flaminicae sive sacerdotes de la Provincia Hispania Citerior: el sacerdocio femenino del culto imperial”, Hispania Antiqua, 37-38, 2013, 137-164 y S. Panzram, "Los flamines provinciae de la Baetica: autorepresentación y culto imperial", Archivo Español de Arqueología, 76, 2003, 121-130.

21. Estos problemas fueron señalados hace ya tiempo por C. Martínez Maza y J. Alvar, en su trabajo sobre el panteón de Málaga ("El mundo de las creencias...", op. cit.) y lo mismo se repite en el norte peninsular, tal y como se puede ver en Ma.C. González-Rodríguez, "Un ejemplo de romanización...”, op. cit.

22. L. Raposo (ed.), Loquuntur saxa. Religiões da Lusitania, Lisboa, 2002; Cardim (coord.), DIIS DEABVSQUE... op. cit. y T. Nogales y J. González (eds.), Culto Imperial: política y poder, Roma, 2007. Sobre el culto imperial, tal y como ya hemos señalado supra, remitimos a la contribución de C. Alarcón en este mismo volumen.

23. J. Mangas, "Los cultos cívicos en la Bética", en C. González Román y A.R. Padilla (eds.), Estudios sobre las ciudades de la Bética, Granada, 2002, 263-275.

24. C. Martínez Maza y J. Alvar, "El mundo de las creencias..., op. cit. y J. Alvar, "El panteón de Carmona...", op. cit.

25. Sobre los cultos de un amplio territorio o de un grupo de población pueden verse, entre otros: J.M. Abascal, "Segobriga y la religión en la Meseta sur durante el Principado", Iberia, 3, 2000, 25-34; A. Tranoy, "Religion et organization du territoire en Galice au Ier siècle de l'empire romain", en L'Aquitania et l' Hispanie septentrionale à l'époque Julio-Claudienne. Organisation et explotation des espaces provinciaux. IVe Colloque Aquitania. Saintes, septiembre 2003, Burdeos, 2005, 119-125; Ch. Bonneaud, "Syncrétisme et divinités classiques en Vettonnie sous le Haut-Empire”, Revista Portuguesa de Arqueología, 7.1, 2004, 385419 y P. Ciprés Torres, "La religión en época alto-imperial", en P. Barruso y J.A. Lema (coords.), Historia del País Vasco. Prehistoria y Antigüedad, San Sebastián, 2006, 327-346. Para el caso de una provincia actual puede servir de ejemplo: M. Pastor Muñoz, "La epigrafía granadina como forma de difusión de la religión 
Igualmente, se han realizado trabajos interesantes sobre la difusión de distintos cultos romanos ya sea referidos a una zona concreta o al conjunto de Hispania. Se pueden citar, entre otros (y además de los referidos al culto imperial), el de G. Baratta sobre Mercurio ${ }^{26}$; el de F. Beltrán LLoris sobre Iuppiter Repulsorius y Solutorius ${ }^{27}$; el de R. Hernando Sobrino sobre Hércules ${ }^{28}$; el de G. Lara Vices sobre Juno ${ }^{29}$; el de B. Goffaux sobre el Genius ${ }^{30}$ y uno de los más significativos, por romper con los tópicos habituales sobre el culto a esta divinidad, el de P. Le Roux sobre Marte, divinidad que debe valorarse -como en otras provincias occidentales $^{31}$ - como un dios urbano integrado en el culto ciudadano y que no parece sustituir, como se venía defendiendo, a los pretendidos dioses guerreros «indígenas» $\mathrm{o}$ «prerromanos».

Sin duda, el marco de referencia general para la comprensión de los diferentes cultos en las civitates de las distintas zonas de Hispania es la consideración de que en el sur y el este peninsular los dioses vivían en ciudades desde hacía tiempo, a diferencia de la conocida como área indoeuropea de Hispania, en la que el paisaje no era el del marco ciudadano y urbanizado. Sin embargo, también en esta zona -como vienen demostrando diferentes trabajos de S. Alfayé Villa, F. Marco Simón y nosotros mismos- la epigrafía evidencia la extensión del modelo de la religión cívica. Esta es una realidad que han puesto de relieve los estudios más recientes sobre los cultos locales, los considerados y denominados tradicionalmente como cultos «indígenas» o prerromanos.

Sobre este tipo de cultos destacan, por un lado, los trabajos de J. C. Olivares Pedreño ${ }^{32}$ referidos al área indoeuropea en general o a alguna divinidad en particular que han permitido un

romana”, en Espacios, usos y formas... op. cit., 259-273. Sobre los cultos en diferentes civitates resulta útil la comparación entre panteones de ciudades con diferente grado de desarrollo histórico y características urbanas como pueden ser, por ejemplo, el caso de Mérida (conventus Emeritensis) y el de la civitas Zoelarum (conventus Asturum): B. Goffaux, "Formes d'organisation des cultes dans la Colonia Augusta Emerita (Lusitanie)", en M. Dondin-Payre y M.Th. Raepsaet-Charlier (eds.), Sanctuaires, pratiques cultuelles et territoires civiques dans l'Occident romain, Bruselas, 2006, 51-97 y P. Rothenhoefer, "Te rogo, oro, obsecro...Bemerungen zu indigenen Kulten in Mérida”, en Espacios, usos y formas... op. cit., 307-318 y A. Redentor, "Manifestações religiosas e onomástica na civitas Zoelarum", Conimbriga, 45, 2006, 233-253.

26. G. Baratta, Il culto di Mercurio nella Penisola Iberica, Barcelona, 2000. A este puede añadirse: P.R. Moya Maleno, "Mercurio en la epigrafía hispanorromana: el ara votiva de Laminium (Alhambra, Ciudad Real)", Revista de Estudios del Campo de Montiel, 1, 2009, 101-123.

27. F. Beltrán Lloris, "Iuppiter Repulsor(ius) y Iuppiter Solutorius: dos cultos provinciales de la Lusitania interior", Veleia, 18-19, 2001-2002, 117-128.

28. Ma .R. Hernando Sobrino, "Hércules en la Meseta. Testimonios, carácter y conexiones", en J. Mangas y M.A. Novillo (eds.), Santuarios suburbanos... op. cit., 383-411.

29. G. Lara Vives, El culto a Juno en Ilici y sus evidencias, Villena, 2005.

30. B. Goffaux, "Le culte au génie de la cité dans la Péninsule iberique”, Pallas, 66, 2004, 157-179.

31. P. Le Roux, “Mars dans la Péninsule Ibérique au Haut-Empire romain”, en Brouquier-Reddé, Bertrand et alii (eds.), Mars en occident... op. cit., 87-95. A este estudio puede añadirse un hallazgo más reciente sobre el culto a esta divinidad: Ma.C. González-Rodríguez y M. Ramírez Sánchez, "Una nueva dedicación a Marte en Bembibre (León)", Veleia, 32, 2015, 209-215.

32. Entre los numerosos trabajos de este investigador pueden destacarse: J.C. Olivares Pedreño, Los dioses de la Hispania céltica, Madrid, 2002; id., "El dios Aernus y los zoelas", Iberia, 5, 2002, 65-77; id., "Cultos

Revista de historiografía 28, 2018, pp. 73-94 
mejor conocimiento de la geografía religiosa en esta zona y, por otro, y muy especialmente, los de S. Alfayé Villa y F. Marco Simón ${ }^{33}$ que desde hace tiempo vienen demostrando que en este territorio de Hispania la epigrafía evidencia también la extensión del modelo de la religión cívica. Esta es una realidad que también nosotros venimos comprobando de forma detallada desde hace años con nuestros proyectos continuados sobre religión y civitas en el noroeste peninsu$\operatorname{lar}^{34}$. El desarrollo de estos proyectos nos ha permitido profundizar en el análisis de los cultos cívicos de esta zona de Hispania y lograr algunos avances significativos para la comprensión de los cultos locales (los considerados tradicionalmente como «indígenas» o «prerromanos») que pueden servir de paradigma para la valoración de los sacra locales del área indoeuropea de Hispania que no deben ser valorados aisladamente y al margen del resto de los cultos cívicos atestiguados en las civitates de esta zona de peninsular.

Los mencionados avances se han producido en los siguientes ámbitos:

A) En el ámbito cuantitativo, la depuración de las fuentes epigráficas - gracias al trabajo de campo $^{35}$ - y a las autopsias de las piezas conservadas nos ha permitido establecer una lista lo más segura posible de los nombres de dioses locales en los tres conventus del noroeste y hemos podido suprimir los teónimos mal leídos, como es, por ejemplo, el caso del pretendido Deis Equeunub(o) en un epígrafe conservado en la localidad de La Vid (Pola de Gordón, León) que una vez examinado con detenimiento el texto se ha visto y comprobado que debe

romanos e indigenismo: elementos para el análisis del proceso de romanización religiosa en la Hispania céltica", Lucentum, XXV, 2006, 139-157; id., "Interpretatio epigráfica y fenómenos de sincretismo religioso en el área céltica de Hispania", Hispania Antiqua, XXXII, 2008, 213-248 e id., "El culto a Júpiter, deidades autóctonas y el proceso de interacción religiosa en la céltica hispana”, Gerión, 27.1, 2009, 331-360.

33. S. Alfayé Villa, "Relecturas de algunas inscripciones latinas de la cueva-santuario de La Griega, Pedraza (Segovia)", Veleia, 31, 2014, 279-288; F. Marco Simón, "Las inscripciones religiosas hispanas de ámbito rural como expresión del hábito epigráfico”, en Espacios, usos y formas... op. cit.,197-210 y S. Alfayé Villa, "Expresiones religiosas..., op. cit.

34. Nos referimos a tres proyectos de investigación de I+D+I: HUM2005-02850; HUM2008-0358HIS y HAR2011-25370 (www.religio.es).

35. Ma.C. González-Rodríguez y F. Marco Simón, "Divinidades y devotos indígenas en la Tarraconensis: las dedicaciones colectivas", Palaeohispanica, 9, 2009, 65-81; Ma.C. González-Rodríguez, "Revisiones epigráficas del corpus de Gallaecia: nuevos hallazgos y viejos problemas”, en Hofeneder y de Bernardo Stempel (eds.), Théonymie celtique, cultes... op. cit., 11-25; Ma.C. González-Rodríguez y M. Ramírez Sánchez, "Hacia la elaboración del corpus de divinidades locales de Gallaecia (Hispania Citerior): novedades y revisiones epigráficas", en W. Eck y P. Funke (eds.) Akten XIV Congressus Internationalis Epigraphiae Graecae et Latinae. Corpus Inscriptionum Latinarum: Auctarium, Series Nova, Volumen Quartum, Berlín, 2014, 573575. El problema principal es la casi total ausencia de contextos arqueológicos de los hallazgos epigráficos. Véase al respecto: S. Alfayé Villa, Ma.C. González-Rodríguez y M. Ramírez Sánchez, "La arqueología del culto a las divinidades locales en el Noroeste hispano", en J.M. Alvárez, T. Nogales e I. Rodá (eds.), Actas XVIII Congreso Internacional de Arqueología Clasica-Proceedings XVIIIth International Congress of Classical Archaeology, vol. II, Mérida, 2014, 1727-1730. 
ser leído como Deis Queunuris ${ }^{36}$. La realización de autopsias de los epígrafes sagrados del área indoeuropea de Hispania con mención de teónimos locales es una tarea básica en esta zona de Hispania debido a la complejidad de los nombres de divinidades (en muchos casos bimembres y trimembres ${ }^{37}$ ) atestiguados en esta área geográfica por lo que resulta, en muchas ocasiones, complicada tanto su lectura segura como su reconstrucción.

En otras palabras, hemos purgado las fuentes epigráficos para poder trabajar sobre documentos lo más seguros posible. Esta es una tarea lenta y ardua que hoy nos permite poder acercarnos a los cultos locales del noroeste en época romana con más seguridad que hace una década.

B) Al mismo tiempo hemos profundizado en el análisis de las fórmulas sagradas utilizadas y en el estudio de los soportes utilizados en la epigrafía religiosa del noroeste para poder establecer con la mayor certeza posible si ambos son o no los mismos que se utilizan en las dedicaciones a las divinidades romanas ${ }^{38}$. Ello nos ha permitido constatar la adopción provincial de los ritos romanos (tal y como reflejan también las fórmulas utilizadas como es el caso de v.s.l.m. y sus variantes; pro salute; ex visu..., etc.). Es decir, que los dioses locales -lo que no equivale a considerarlos inmutables- entendían el mismo lenguaje que las divinidades romanas y se habían acostumbrado al carácter bilateral del votum romano tal y como permiten comprobar, incluso, algunas fórmulas escasamente representada en la epigrafía votiva del occidente del Imperio ${ }^{39}$.

36. S. Alfayé Villa, Ma.C. González-Rodríguez y J. Gorrochategui Churruca, "Deis Queunur(is): nuevo teónimo del Noroeste hispano. Relectura del ara de La Vid (Pola de Gordón, León. Hispania Citerior)”, Veleia, 29, 2012, 415-424.

37. Puede verse al respecto, entre otros, J. De Hoz, F. Fernández Palacios y E. Luján, "La 'frontera religiosa' y los teónimos indígenas de la Hispania central y oriental", en Cardim (coord.), DIIS . DEABUSQUE... op. cit., 195-238 y Ma.C. González-Rodríguez, "Die lateinische...", op. cit.; ead., "Noms des divinités préromaines...", op. cit. En el caso de la epigrafía del noroeste, la constatación de las dificultades de lectura y de reconstrucción de algunos teónimos nos ha llevado, en general, a reducir considerablemente la lista habitual de nombres de divinidades denominadas indígenas. También hemos revisado, revisitado y puesto en entredicho el propio carácter votivo de algunos epígrafes como es el caso de ERA 11 considerada como una dedicación a una divinidad cuyo nombre resulta difícil de reconstruir, debido al estado de conservación del soporte y que ha sido objeto de distintas restituciones como Iovio, [Cos]iovio, [Du]lovio, [Lug]ovio Tabaliaeno e incluso I(ovi) O(ptimo) [M(aximo)] (González-Rodríguez y Marco Simón, "Divinidades y devotos...", op. cit., 66-68). Según hemos intentado demostrar en este trabajo lo más probable es que se trate de un epígrafe funerario y no sagrado, tal y como hasta el presente se había defendido.

38. Puede verse al respecto: González-Rodríguez y Marco Simón, "Divinidades y devotos..., op. cit. y Ma.C. González-Rodríguez y M. Ramírez Sánchez, "Observaciones sobre la fórmula in hono. Argael. en un epígrafe de Cacabelos, León (CIL II 5672)”, Palaeohispanica, 10, 2010, 63-79.

39. Cabe destacar la inusual fórmula voti compotem aliquem facere constatada en CIL II 2601. Sobre este formulario y su significado véase ahora $M^{a}$.C. González-Rodríguez y E. Ortiz-de-Urbina Álava, "La fórmula voti compotem aliquem facere y sus variantes en la epigrafía latina del occidente romano", Epigraphica, LXXIX, 2017, 253-273. Un formulario similar se ha encontrado también en un epígrafe de la Bética, tal y

Revista de historiografía 28, 2018, pp. 73-94 
Los formularios recogidos y analizados nos permiten llegar a la conclusión de que el rito romano -el único que ha llegado hasta nosotros y que conocemos en esta parte de Hispania- era también en esta zona un acto de comunicación muy eficaz entre las divinidades locales y sus cultores ${ }^{40}$.

C) A nivel cualitativo, el aspecto más importante desde el punto de vista histórico, hemos planteado el análisis de estas divinidades en el marco del proceso de aculturación en el que se ven inmersas, relacionándolas con la nueva organización de las comunidades. Esta manera de ver nos ha permitido y aconsejado abandonar la vieja terminología de dioses «indígenas» o "prerromanos» -la habitual en la historiografía sobre estos cultos- y sustituirla por el de divinidades locales que pasan a formar parte del funcionamiento institucional de las civitates. En esta línea, hemos intentado establecer las combinaciones divinas de algunas de las comunidades del Noroeste -aquellas que ofrecen más información al respecto y cuyos «lugares centrales» son suficientemente conocidos- como sucede en los casos de Aquae Flaviae; Bracara Augusta; Lucus Augusti; Asturica Augusta y la civitas Zoelarum y cuya heterogeneidad nos ha permitido observar la diversidad y complejidad de los panteones en esta parte de Hispania ${ }^{41}$. Entre todas ellas, el municipio flavio de Aquae Flaviae puede servir perfectamente como modelo de referencia ya que su reconocido y documentado estatuto jurídico permite trasponer aquí grosso modo las normas que regían la vida religiosa de los municipios del occidente del imperio, tal y como documenta en la Bética la lex Irnitana. La epigrafía votiva de la capital de este municipio ofrece un rico panteón en el que destacan las dedicaciones -todas ellas halladas en el centro de la ciudad- a dioses clásicos con epítetos suficientemente elocuentes como Iuppiter Optimus Maximus Municipalis; Tutela Municipi Aquaflaviensium; Concordia Municipum Municipii Aquiflaviensium y los dioses Lares: Tarmucenbaeci Ceceaeci;

como puede verse en J. Saquete, S. Ordóñez y S. García-Dils, "Una votorum nuncupatio en colonia Augusta Firma (Écija, Sevilla)", Zeitschrift für Papyrologie und Epigraphik, 176, 2011, 281-290.

40. Un ejemplo concreto es la utilización de la fórmula ex donis que figura en la dedicación al dios Vago Donnaego en el territorio de la civitas de Asturica Augusta (CIL II 2636). Se trata de una fórmula muy poco usual en la epigrafía votiva latina del occidente del imperio. De hecho este es el único testimonio en Hispania a los que hay que añadir dos más en Mesia inferior y uno en Italia. Esta formulación se constata acompañando a ofrendas de estatuas sufragadas mediante donativos. En este caso también parece que estamos ante una ofrenda oficial (la mención de la respublica de Asturica Augusta así permite afirmarlo) hecha gracias a las donaciones logradas mediante colecta pública. En definitiva, este formulario, al igual que el soporte que lo acompaña -una placa de mármol- (así como el resto de los formularios latinos utilizados en las inscripciones dedicadas a divinidades locales de nombres indígenas) nos indican que también aquí, tal y como recientemente se ha señalado para las provincias noroccidentales del imperio,: «...citoyens romains et pérégrins participent, de façons variées, à la célébration de cultes dont certains remontent, sous une forme indéterminée, à l'époque de l' indépendance, mais sont exprimés sur un mode latin»: M. DondinPayre, "Celtiques? Romains? Indigènes? Importés? Divinités et pratiques religieuses dans l'empire romain d'Occident”, en Charles-Laforgue (Études réunies par), Les religions... op. cit., 75-93 (86).

41. González-Rodríguez, "Sobre la religio..., op. cit. 
Findenetici y Erredici. Estos tres últimos epítetos se documentan en epígrafes hallados en los alrededores del núcleo urbano de la actual Chaves.

Parece, por tanto, que estamos ante el panteón oficial de un municipio flavio, escogido e instaurado por los primeros magistrados ${ }^{42}$ y en el que se documentan, sobre todo, como es propio de una ciudad de estatuto jurídico municipal, los dioses del panteón romano pero, al mismo tiempo, no se borra totalmente el pasado, sólo se adapta y reinterpreta, como ejemplifica el caso de los Lares asociados a determinantes locales. Este y el resto de los diferentes panteones, más o menos heterogéneos, reflejan la complejidad del proceso de aculturación que en el ámbito religioso afectó a los dos panteones en contacto y trajo consigo fusiones, asimilaciones y transferencias que tuvieron que modificar en mayor o menor medida la forma y el fondo de los nuevos dioses ${ }^{43}$.

En resumen, creemos que la comprensión de estas divinidades de nombre indígena debe hacerse no en función de su pasado -como era habitual hasta ahora- entendiéndolas, por la naturaleza de su nombre, como divinidades «indígenas o prerromanas», sino en función de su situación comunitaria, en su civitas y unas con relación a las otras, en las asociaciones religiosas que forman y en la jerarquía de las nuevas combinaciones religiosas ${ }^{44}$.

D) El estudio de estas divinidades no se ha hecho de forma aislada sino que, por el contrario, hemos prestado atención a un aspecto hasta ahora bastante olvidado, el de la naturaleza y el estatus jurídico y social de los dedicantes lo que nos ha permitido establecer -en la medida de lo posible- las diferencias entre dedicaciones públicas y privadas. Nuestro interés ha sido romper la separación que hasta ahora había entre una lista de dioses «indígenas» y la falta de información sobre los devotos que les rendían culto. Consecuencia de este interés han sido los trabajos, entre otros, de $\mathrm{M}^{\mathrm{a}} \mathrm{C}$. González-Rodríguez y F. Marco Simón en el que se estudian las dedicaciones colectivas en la Tarraconense ${ }^{45}$ y muy especialmente los que viene realizando E. Ortiz-de-Urbina ${ }^{46}$ sobre los cultores de estas divinidades en el conventus

42. Sobre las competencias religiosas de los duunviros véase J.F. Rodríguez Neila, "Los duunviros, la ciudadanía y la gestión de la política municipal”, en Ortiz-de-Urbina Álava (ed.), Magistrados locales... op. cit, 189-228 (en especial, 210-212).

43. Sobre este proceso véanse los trabajos citados supra de Van Andringa.

44. Tal y como Van Andringa, La religion... op. cit; id., "Religion and the Integration..." op. cit.; id., "New Combinations and new statutes...” op. cit. viene planteando para el caso de las Galias.

45. González-Rodríguez y Marco Simón, “Divinidades y devotos...”, op. cit.

46. E. Ortiz-de-Urbina Álava, "Cultores de divinidades indígenas en el conventus Asturum: onomástica personal y condición cívica”, en J.M. Abascal, A. Caballos, S. Castellanos y J. Santos (eds.), Estudios de Historia Antigua en homenaje al profesor Manuel Abilio Rabanal Alonso, Sevilla, 2012, 185-218; ead., "Dedicantes y devotos de las divinidades indígenas en el conventus Asturum (Hispania citerior)”, en Eck y Funke (eds.), Akten XIV Congressus Internationalis... op. cit., 576-579; ead., "Onomastic practice and socio-juridical condition: on dedicants of indigenous deities in the conventus Asturum (Hispania citerior)", Quaderni Lupiensi di Storia e Diritto, 4, 2014, 95-116. Véase también su contribución en este mismo volumen. A estos trabajos sobre el noroeste deben añadirse: S.Ma. García Martínez, "La implicación del colectivo femenino en los cultos indígenas y latinos del Conventus Bracaraugustanus”, Revista de Guimarães, 110, 2000,165-

Revista de historiografía 28, 2018, pp. 73-94 
Asturum y, en general, en todo el noroeste. Su análisis permite constatar el predominio de la onomástica latina y de un alto porcentaje de individuos con tria nomina que por la cronología de las inscripciones serían miembros de pleno derecho de comunidades favorecidas por el Ius latii.

E) Y por último, se ha llevado a cabo, por parte de S. Alfayé Villa ${ }^{47}$, una revisión crítica de la iconografía asociada a las inscripciones con teónimos locales seguros o «supuestos» que permite hoy una aproximación mucho más segura a un material complejo, difícil y en ocasiones alterado o «inventado ${ }^{48}$.

En resumen, la labor realizada con nuestro proyecto ha permitido, a través del estudio de las divinidades locales de una zona concreta de la Hispania indoeuropea, una aproximación al conocimiento del carácter dinámico y evolutivo de los sistemas politeístas de la religión hispanorromana y comprobar, una vez más -como cuando estudiamos la epigrafía funeraria relativa a las unidades organizativas denominadas «indígenas» documentadas también en el área indoeuropea- que las fuentes epigráficas disponibles son todas de época romana y ofrecen información de y para esta época y no para el periodo histórico anterior o época conocida como prerromana. Estas fuentes ponen de manifiesto tanto los elementos romanos (soportes epigráficos; divinidades; fórmulas votivas; sacerdocios, etc.) como la

188; ead. y M.A. Rabanal Alonso, "El culto a Júpiter en el Conventus Bracaraugustanus: los dedicantes y su condición social", Estudios Humanísticos. Geografía, historia y arte, 22, 2001, 11-28 y H. Gallego Franco, "La mujer en las estructuras religiosas de Hispania septentrional: consideraciones en base a la epigrafía votiva hispanorromana del territorio castellano-leonés", Ilu, 9, 2004, 69-89. Sobre los cultos hispanorromanos en general: A. Lozano Velilla, "Aspectos sociológicos de los cultos hispanoromanos", en Cardim (coord.), DIIS. DEABUSQUE.... op. cit., 283-294 y J.C. Olivares Pedreño, "La omisión del dedicante en las inscripciones votivas de Hispania como indicio de su ubicación en ámbitos privados", Studia Historica. Historia Antigua, 31, 2013, 59-87. Para el caso de la Lusitania: M.L. Barberana Núñez y J.L. Ramírez Sádaba, "Los devotos de las divinidades indígenas en Lusitania. El paradigma de Lancia Oppidana, Caurium, Capera, Augusta Emerita y Metellinum", en Dedicanti e cultores nelle religioni celtiche. VIII Workshop F.E.R.C.A.N., Milán, 2008, 9-42. Igualmente, en este ámbito debe destacarse el estudio llevado a cabo por S. Alfayé Villa, "Hacia el lugar de los dioses: una aproximación a la peregrinación religiosa en la Hispania indoeuropea”, en F. Marco Simón, F. Pina Polo y F. Remesal (eds.), Viajeros, peregrinos y aventureros en el mundo antiguo, Barcelona, 2010, 177-218 sobre el fenómeno de las peregrinaciones en la Hispania indoeuropea en época romana.

47. S. Alfayé Villa, "La iconografía divina en Celtiberia: una revisión crítica", Archivo Español de Arqueología, 76, 2003, 77-96; ead., Imagen y ritual en la Céltica peninsular, A Coruña, 2011 y ead., "Sobre iconografía y teonimia en el Noroeste peninsular", Paleohispanica, 13, 2013, 189-208.

48. Un ejemplo paradigmático lo constituye el pretendido o imaginario dios Anodio en una inscripción procedente de Chao do Castro, O Bolo (Orense) con una supuesta representación de la divinidad y cuyo texto había sido leído como Anod/io M(artius) Sigir(us) (HEp 3, 273). Se trata de una inscripción perdida, pero hemos podido ver las fotografías de la pieza antes de desaparecer y comprobar que se trata de un epígrafe moderno cuya lectura es an(no) $d(e)$ y la representación iconográfica es la de una cruz cristiana muy semejante a la que aparece en el cruceiro y peto de animas que existe en el propio Chao do Castro fechado en el s. XVIII. Véase al respecto Alfayé Villa, “Sobre iconografía...”, op. cit., 189-190. 
adaptación y transformación de las divinidades locales (nombres de divinidades no clásicas) bajo el efecto de la romanización institucional de las comunidades a las que están ligadas. Y esta característica se repite también, como veremos a continuación, en el estudio de los lugares -el espacio concreto- en el que estos cultos y los ritos a ellos asociados se desarrollan.

\section{Lugares de culto (loca sacra)}

Los lugares de culto constituyen un aspecto muy importante en el estudio de la religión hispanorromana ya que configuran la parte más visible del paisaje religioso y cumplen un papel nada desdeñable en la vertebración del territorio de las civitates.

En el estudio de los lugares de culto cívicos (loca sacra) contamos actualmente con dos obras generales y muy significativas sobre el tema. Se trata de las Actas de sendos congresos, la primera editada en 2009 por P. Mateos, S. Celestino, A. Pizzo y T. Tortosa ${ }^{49}$, con atención prácticamente exclusiva -salvo dos contribuciones de un total de 26- a las fuentes arqueológicas y la arquitectura sagrada y la segunda, más reciente, del año 2014 -aunque los trabajos corresponden a un Congreso de varios años antes-, editada por J. Mangas y M.A. Morillo ${ }^{50}$ sobre santuarios suburbanos y del territorio de las ciudades romanas. Esta última publicación presenta el interés de ocuparse tanto de fuentes arqueológicas como escritas. Los títulos de ambas obras son suficientemente elocuentes al unir los dos conceptos básicos: santuarios y ciudades pero, en nuestra opinión, se echa en falta en ambos casos un capítulo introductorio de carácter metodológico en el que se aborde o reflexiones sobre la problemática de las fuentes; sobre la terminología referida a los lugares de culto en la civitas romana ${ }^{51}$; sobre la misma definición de santuario en el mundo romano y sobre los desplazamientos de culto que pueden ir unidos a los cambios culturales para evitar la generalización de la idea que un mismo santuario puede perdurar siglos y traspasar épocas -desde época prerromana hasta la edad media-. Un capítulo introductorio de estas características facilitaría al lector la comprensión del contenido y finalidad de la obra que parece obedecer, en algunos casos, únicamente a la acumulación de datos. En cualquier caso, se debe reconocer como un mérito importante de la segunda de las Actas mencionadas la demostración de que en el territorio de las civitates romanas, en el ager, no solo moraban los dioses locales, que habitualmente se asociaban al ámbito rural, sino también los romanos.

$\mathrm{Al}$ margen de las contribuciones recogidas en estas Actas, los avances en el estudio de los lugares de culto han venido de la mano, por un lado, del incremento de los trabajos ar-

49. P. Mateos, S. Celestino, A. Pizzo y T. Tortosa (eds.), Santuarios, oppida y ciudades: arquitectura sacra en el origen y desarrollo urbano del Mediterráneo occidental, Mérida, 2009.

50. Mangas y Novillo, (eds.), Santuarios suburbanos... op. cit.

51. Sobre la terminología referida a los loca sacra constatados epigráficamente puede verse: $\mathrm{M}^{\mathrm{a}}$.C. González-Rodríguez, "La epigrafía de los espacios sagrados”, en Actas de los XVIII Cursos Monográficos sobre el patrimonio histórico. Cursos sobre el patrimonio histórico 12, Santander, 2008, 37-56 y ead., "Santuarios y epigrafía en las ciudades hispanorromanas: una aproximación”, en Mateos, Celestino, Pizzo y Tortosa (eds.), Santuarios, oppida... op. cit., 407-416. 
queológicos ${ }^{52}$ en el oppidum y el ager de las diferentes civitates $^{53}$ y, por otro, de la comprensión global de algunos lugares de culto hasta ahora valorados como «indígenas» $\mathrm{O}$ «prerromanos». En este último ámbito destacan muy especialmente los trabajos de S. Alfayé Villa ${ }^{54}$ sobre los santuarios naturales del área indoeuropea que permiten valorar, por primera vez en la historiografía hispana, estos espacios de culto como santuarios inmersos en un horizonte cultural y cultual plenamente romanos desde el que se pueden explicar y encontrar numero-

52. Hasta hace poco tiempo en los manuales sobre religión romana, en general y de Hispania en particular, apenas se recurría a las fuentes arqueológicas. Esta fuente era considerada solo un complemento de la información de las fuentes escritas. De hecho, la integración de los datos arqueológicos e iconográficos como fuente para la historia de la religión (romana) es un hecho reciente y debe mucho al estudio de los mundos periféricos y sus cultos (en especial al análisis de los llamados santuarios célticos ). El caso hispano no es ajeno a esta tendencia, sin embargo, por fortuna, en los últimos años han aparecido interesantes trabajos que se ocupan, sobre todo, del estudio de los restos arqueológicos de diferentes ciudades y se ha reflexionado sobre diferentes problemas relacionados con la arquitectura sacra.

53. Sobre la transmisión de los estilos y modelos arquitectónicos en diferentes ciudades de la Bética pueden verse, entre otros, C. Márquez, "Baetica templa”, en J. Ruiz de Arbulo (ed.), Simulacra Romae. Roma y las capitales provinciales del occidente europeo, Tarragona, 2004, 109-127; J.F. Murillo et alii, "El templo de la C/ Claudio Marcelo (Córdoba). Aproximación al foro provincial de la Bética”, Romula 2, 2003, 53-88 y A. Ventura, "Reflexiones sobre la arquitectura y la advocación del templo de la calle Morería en el forum adiectum de colonia Patricia Corduba”, en Nogales y González (eds.), Culto imperial... op. cit., 215-238; P. Pensabene J. Ruiz de Arbulo, D. Vivó y R. Mar, "El capitolio de Tarraco, identificación y primeras observaciones”, en D. Vaquerizo y J.F. Murillo (eds.), El concepto de lo provincial en el mundo antiguo. Homenaje a la profesora Pilar León, vol. 1, Córdoba, 2006, 391-418; J.N. Bonneville et alii, Belo VII. Le capitole, Madrid, 2002; S. Ordóñez Agulla y S. García-Dils de la Vega, "Evidencia de inscripciones monumentales asociadas al templo principal de la colonia Augusta Firma”, Habis, 44, 157-184 y S. GarcíaDils de la Vega, Colonia Augusta Firma Astigi. La evolución urbana de Écija desde la Protohistoria hasta la Antigüedad tardía, Sevilla, 2015 (en especial, el capítulo 9: Espacios y edificios públicos); J.M. Alvárez y T. Nogales, Forum Coloniae Augusta Emerita. Templo de Diana, Mérida, 2003 y R. Ayerbe Vélez, T. Barrientos Vera y F. Palma García (eds.), El Foro de Augusta Emerita. Génesis y evolución de sus recintos monumentales, Mérida, 2009 y para los lugares de culto de Contributa Iulia: P. Mateos, "Un santuario urbano hallado en 'Contributa Iulia' (Medina de las Torres, Badajoz)”, Lucentum, 34, 2015, 231-246; etc, etc.

54. S. Alfayé Villa, Santuarios y rituales en la Hispania Céltica, Oxford, 2009; ead., "Hacia el lugar de los dioses...”, op. cit., 177-218; S. Alfayé Villa y F. Marco Simón, “El santuario de Peñalba de Villastar (Teruel) y la romanización religiosa en la Hispania indoeuropea”, en X. Dupré Raventós, S. Ribichini y S. Verger (A cura di), Saturnia Tellus. Definizioni dello spazio consacrato in ambiente etrusco, italico, fenicio-punico, iberico e celtico: Atti del convegno internazionale svoltosi a Roma dal 10 al 12 novembre 2004, Roma, 2008, 507-526; S. Alfayé Villa y F. Marco, "Santuarios en canteras y romanización religiosa en Hispania y Gallia”, en Mangas y Novillo (eds.), Santuarios suburbanos... op. cit., 53-86; S. Alfayé Villa, “Expresiones religiosas...”, op. cit. y S. Alfayé Villa, González-Rodríguez, Ramírez Sánchez, “La arqueología...” op. cit. A estos trabajos pueden añadirse, entre otros: Ma.C. González-Rodríguez, "Los santuarios del territorio en las civitates de la Asturia augustana: el ejemplo del Deus Vagus Donnaegus", en Mangas y Novillo (eds.), Santuarios suburbanos... op. cit, 205-223 y J.M. Iglesias Gil y A. Ruiz Gutiérrez, "Flaviobriga y el santuario de Salus Umeritana”, en Mangas y Novillo (eds.), Santuarios suburbanos... op. cit., 277-294. 
sos paralelos y, en ocasiones, como espacios liminales de culto que ofrecen protección en los márgenes de las civitates.

En este campo se debe destacar también el interesante estudio de A. Garrido, R. Mar y M. Martins sobre el santuario conocido como la Fonte do Ídolo (Braga, Portugal ${ }^{55}$ hasta ese momento considerado un santuario «indígena». Tras el análisis minucioso de la documentación epigráfica, los restos arqueológicos y las representaciones iconográficas estos investigadores demuestran que este lugar de culto fue integrado, en el s. I, en los cánones del sistema cultural y cultual romano y muestra, de forma elocuente, el cambio de mentalidad y de patrones de representación que se ocultan bajo el proceso de romanización. La misma valoración es válida, en nuestra opinión, para el santuario de Revve Anabaraego localizado en As Burgas (Ourense) -territorio de la civitas de Aurium- ${ }^{56}$. Este lugar de culto puede ser entendido como un santuario salutífero consagrado a una divinidad local Revve Anabaraego, según constatan las seis aras localizadas in situ y halladas en contexto arqueológico y que se pueden fechar en los primeros años del siglo I de la era. Por el momento, no se ha encontrado ningún resto de época anterior que lo pueda vincular con una frecuentación en época prerromana; los dedicantes presentan mayoritariamente onomástica latina y su estatus jurídico es, en su mayoría, el de libertos ${ }^{57}$. En conjunto, por las características que presenta -las propiedades del agua; su ubicación en el territorio de una ciudad; la frecuentación de fieles y la presencia de exvotos- parece tratarse de un santuario cuyo papel en la civitas de Aurium puede comprenderse y explicarse si se lo compara con el santuario de las fuentes de Clitumnus en la Umbria italiana, atribuido por Augusto a la colonia de Hispellum y descrito magistralmente por Plinio el Joven (Ep., VIII, 8).

Pasando del ámbito de las ciudades al de las capitales provinciales, en lo que llevamos de siglo han sido importantes los avances logrados en los estudio de los conjuntos de culto imperial a nivel provincial. En este caso destacan, entre otros, los trabajos llevados a cabo en la capital de la Citerior y en la de Lusitania ${ }^{58}$.

55. A. Garrido, R. Mar y M. Martins, A fonte do Ídolo. Análise, interpretaçao e reconstituçao do santuario, Braga, 2008.

56. J.M. Eguileta y C. Rodríguez Cao (Coords.), Aqua, divi, urbs. Auga, deuses e cidade. Excavacións arqueológicas nas Burgas (Ourense): Casa dos Fornos e traseiras das rúas do Vilar, Cervantes e do Baño, Ourense, 2012 y J.M. Eguileta y C. Rodríguez Cao (eds.), Aqua, divi, urbs. Agua, dioses y ciudad. Excavaciones Arqueológicas en As Burgas (2005-2010), Ourense, 2016. Sobre este tipo de lugares de culto véase también: F. Diez de Velasco, "Mutation et perduration de l'espace sacré: l'exemple du culte des eaux thermals dans la Péninsule Ibérique jusqu' à la romanisation”, en Dupré, Ribichini y Verger (A cura di), Saturnia Tellus..., op. cit., 457-469.

57. Ma.C. González-Rodríguez, "As dedicacións a Revve Anabaraego no marco da relixión romana provincial da época altoimperial”, en Eguileta y Rodríguez Cao (coords.), Aqua, divi, urbs... op. cit., 59-81.

58. Véanse los trabajos citados en la contribución sobre el culto imperial en este mismo volumen. 


\section{Cuestiones pendientes}

A modo de conclusión queremos señalar que, pesar de los avances conseguidos, aún quedan muchos problemas y lagunas por resolver y retos para el futuro.

Se han podido reconstruir algunas piezas del complicado puzzle referido a la religión hispanorromana pero faltan aún muchas otras para poder dibujar una visión coherente y completa del paisaje religioso de época romana en buena parte de Hispania, entendiendo el paisaje religioso -como muy acertadamente han señalado J. Scheid y F. de Polignac ${ }^{59}-$ tanto en su materialidad (visible) como metafórica, como el lugar de encuentro de identidades religiosas múltiples (y negociadas).

Es necesario seguir profundizando en el estudio global de los lugares de culto hispanorromanos teniendo muy presente que en el caso de los santuarios consagrados a divinidades locales podemos estar ante divinidades y cultos que han sufrido una reelaboración con el paso de las comunidades al estatuto cívico y, además, que esta transformación ha evolucionado durante tres o cuatro siglos, si se tiene en cuenta que algunas fuentes epigráficas y arqueológicas del área del noroeste se fechan en los ss. III y IV. Baste citar a este respecto el ejemplo más paradigmático, el del santuario dedicado al dios Lar Berobreo en Facho de Donón (Pontevedra), un lugar de culto muy difícil de comprender, valorar y explicar -a pesar de los esfuerzos de sus excavadores- y en el que se han documentado más de un centenar de inscripciones sagradas que omiten el nombre de los cultores ${ }^{60}$.

En buena parte de Hispania y en relación con los cultos, especialmente los locales, sigue siendo necesaria una revisión, depuración y contextualización de las fuentes epigráficas lo que equivale a subrayar la necesidad de la realización sistemática de autopsias de un buen números de inscripciones sagradas, sobre todo y especialmente en todo el occidente peninsular y, en general, en la llamada área indoeuropa de Hispania. Piénsese, por ejemplo, en la zona de la actual Extremadura, un área con una rica e interesantísima epigrafía ${ }^{61}$ así como en

59. Scheid et de Polignac, "Qu'est-ce qu' un 'paisage religieux'?",... op. cit.

60. Th. Schattner, J. Suárez Otero y M. Koch, "Monte do Facho, Donón (O Hio. Prov. Pontevedra) 2003. Informe sobre las excavaciones en el santuario de Berobreus", Archivo Español de Arqueología, 77, 2004, 23 71; M. Koch, "El santuario dedicado a Berobreo en el monte Do Facho (Cangas, Galicia)", Palaeohispanica, 5, 2005, 823-836; Th. Schattner, J. Suárez Otero y M. Koch, "Monte do Facho, Donón (O Hio. Prov. Pontevedra) 2004. Informe sobre las excavaciones en el santuario de Berobreo", Palaeohispanica, 6, 2006, 183-223; M. Koch, Th. Schattner y J. Suárez Otero, "Weihaltäre im Heiligtum des deus lar Berobreus auf dem Monte Facho (O Hio, Galicien)", en A. Busch y A. Schäfer (eds.), Weihaltäre in Kontext, Friedberg, 2014, 249-268; J. Suárez Otero, "Monte do facho, castro ou santuario?: a campaña do 2008 e arquitectura sacra na cultura castrexa", Portugalia, 36, 2015, 295-312 y M. Koch, Die epigraphische Hinterlassenschaft des Heiligtum auf dem Monte do Facho (o Hio/Cangas), Madrid, 2015 (inédito). Agradecemos a este último investigador el habernos permitido consultar este corpus inédito.

61. Tal y como puede verse en el caso de un epígrafe conservado en la localidad de Tejeda de Tiétar (Cáceres) recientemente estudiada por S. Alfayé Villa, P. de Bernardo Stempel, Ma. C. González-Rodríguez y M. Ramírez Sánchez, "La diosa Du(v)itera en una inscripción de Tejeda de Tiétar (Cáceres, HEp 3, 1993, 139)", en R. Häussler \& T. King (ed.), Celtic Religions in the Romana Period. Personal, Local and Global (Celtic Studies Publications XX), Aberystwyth, 2017, 209-230. 
la necesaria revisión y actualización del material epigráfico referido al culto imperial después del trabajo realizado por R. Étienne hace casi seis décadas ${ }^{62}$. De la misma manera, se debe profundizar y prestar mayor atención al estudio de la sociología de los cultores de las diferentes divinidades (tanto las clásicas como las locales), un tema al que hasta el presente no se le ha prestado la atención debida.

Por último, en el ámbito de las ciudades romanas, municipios y colonias, especialmente en el sur y este peninsular donde los documentos son mucho más ricos se debe seguir investigando y profundizando en cuestiones relacionadas con la posible influencia del poder central en las provincias en relación con asuntos religiosos ${ }^{63}$.

En definitiva, si bien nuestros conocimientos actuales sobre la religión hispanorromana han avanzado desde el siglo pasado, aún existe un enorme e interesante campo de trabajo para las generaciones jóvenes de investigadores que quieran dedicarse al estudio del sistema religioso altoimperial de Hispania.

62. R. Étienne, Le culte impérial dans la péninsule ibérique d’Auguste à Diocletien, París, 1958. Para la historiografía referida al culto imperial en Hispania remitimos a la contribución de C. Alarcón. Por su parte, la epigrafía referida al culto a Júpiter en Hispania ha sido recientemente recogida por A. Moneo Crespo en su tesis doctoral bajo el título Entre religión y poder: el culto a Júpiter en Hispania, Vitoria-Gasteiz, 2016.

63. En este sentido resultan muy interesante las reflexiones y los interrogantes expuestos por Saquete Chamizo, Ordóñez Agulla y García-Dils de la Vega, "Una votorum nuncupatio..., op. cit., 290 sobre la posible existencia de documentos rituales enviados desde Roma a las provincias y el papel del gobernador provincial en asuntos relacionados con el culto imperial. 
